\title{
con \\ Correction: Liao et al. Twelve-Week Lower Trapezius-Centred Muscular Training Regimen in University Archers. Healthcare 2022, 10, 171
}

\author{
Chien-Nan Liao ${ }^{1}$, Chun-Hao Fan ${ }^{2}$, Wei-Hsiu Hsu ${ }^{2,3,4, *(\mathbb{D})}$, Chia-Fang Chang ${ }^{2}$, Pei-An Yu ${ }^{2,3}$, \\ Liang-Tseng Kuo ${ }^{2,3} \mathbb{C}, \mathrm{Bo}^{-L i n g ~ \mathrm{Lu}^{2}}$ and Robert Wen-Wei Hsu ${ }^{2,3}$
}

check for

updates

Citation: Liao, C.-N.; Fan, C.-H.; Hsu, W.-H.; Chang, C.-F.; Yu, P.-A.; Kuo, L.-T.; Lu, B.-L.; Hsu, R.W.-W.

Correction: Liao et al. Twelve-Week Lower Trapezius-Centred Muscular Training Regimen in University Archers. Healthcare 2022, 10, 171. Healthcare 2022, 10, 378. https:// doi.org/10.3390/healthcare10020378

Received: 28 January 2022 Accepted: 30 January 2022 Published: 17 February 2022

Publisher's Note: MDPI stays neutral with regard to jurisdictional claims in published maps and institutional affiliations.

Copyright: (C) 2022 by the authors. Licensee MDPI, Basel, Switzerland. This article is an open access article distributed under the terms and conditions of the Creative Commons Attribution (CC BY) license (https:// creativecommons.org/licenses/by/ $4.0 /)$.
Department of Athletic Sports, National Chung Cheng University, Chia Yi 621, Taiwan; liao.cody@gmail.com

2 Sports Medicine Center, Chang Gung Memorial Hospital, Chia Yi 621, Taiwan; fun711009@cgmh.org.tw (C.-H.F.); kojia882@yahoo.com.tw (C.-F.C.); b9002065@cgmh.org.tw (P.-A.Y.); light71829@gmail.com (L.-T.K.); bolin271@yahoo.com.tw (B.-L.L.); wwh@cgmh.org.tw (R.W.-W.H.)

3 Department of Orthopedic Surgery, Chang Gung Memorial Hospital, Chia Yi 621, Taiwan

4 School of Medicine, Chang Gung University, Tao-Yuan 333, Taiwan

* Correspondence: 7572@cgmh.org.tw; Tel.: +886-5-36231000 (ext. 2855)

The authors would like to make the following corrections to the published paper [1]. Replacing the Institutional Review Board number 2019800990B0 with 201800990B0.

\section{Reference}

1. Liao, C.-N.; Fan, C.-H.; Hsu, W.-H.; Chang, C.-F.; Yu, P.-A.; Kuo, L.-T.; Lu, B.-L.; Hsu, R.W.-W. Twelve-Week Lower Trapezius-Centred Muscular Training Regimen in University Archers. Healthcare 2022, 10, 171. [CrossRef] [PubMed] 